Eur. J. Clin. Chem. Clin. Biochem.

Vol. 31,1993 , pp. $473-476$

(C) 1993 Walter de Gruyter \& Co. Berlin - New York

\title{
Effect of Temperature, Duration of Storage and Sampling Procedure on Ammonia Concentration in Equine Blood Plasma
}

\author{
By A. Lindner and Sandra Bauer
} Department of Anatomy, Physiology and Hygiene of Domestic Animals, Faculty of Agronomy,
Rheinische Friedrich-Wilhelms-University Bonn, Bonn, Germany

(Received Deccmber 8, 1992/April 19, 1993)

Summary: The effect of storage duration at different storage temperatures on the plasma ammonia concentration of equine EDTA whole blood, EDTA plasma and heparin plasma samples was investigated. Further, the effect of jugular vein compression before and during blood sampling on the plasma ammonia values was evaluated. In EDTA whole blood kept at $4{ }^{\circ} \mathrm{C}$ there was no significant increase of ammonia content after 6 hours of storage, whereas the increase was already significant 3 hours after collection if the EDTA whole blood was kept at $20-22^{\circ} \mathrm{C}$. EDTA plasma samples stored at $20-22^{\circ} \mathrm{C}, 4^{\circ} \mathrm{C}$ and $-20^{\circ} \mathrm{C}$ showed mean ammonia formation rates of $26.8 \mu \mathrm{mol} / 1,6.6 \mu \mathrm{mol} / 1$ and $0.03 \mu \mathrm{mol} / 1$ per day, respectively. There were no differences between ammonia values of EDTA and heparin plasma samples immediately after sampling and following 3 days of storage at $4{ }^{\circ} \mathrm{C}$ and 3 and 90 days of storage at $-20^{\circ} \mathrm{C}$. Although significant, the absolute differences between the mean plasma ammonia contents of EDTA blood sampled with and without compression of the jugular vein were small $(20.2 \pm 4.1 \mu \mathrm{mol} / \mathrm{l}$ and $23.4 \pm 4.3 \mu \mathrm{mol} / \mathrm{l} \mathrm{resp}$.$) .$

\section{Introduction}

In human sports medicine there is great interest in the determination of plasma ammonia for evaluation of the adaptation to exercise and of the performance capacity of athlets $(1-5)$. The same has been true for horses for several years $(6-9)$. However, studies of the effect of equine blood specimen handling procedures on the ammonia concentration are scarce (10), although they are necessary for defining the conditions for the use of plasma ammonia determinations in blood samples collected from horses under field conditions. From work done on human blood samples it is known that handling procedures affect the ammonia values $(11,12)$. However, data gained for human blood samples may not be valid for horses due to species differences, as demonstrated by Ogilvie et al. (10) for cats and horses. Therefore, in this study the effect of storage time of equine EDTA whole blood, heparin and EDTA plasma at different temperatures on plasma ammonia concentrations was investigated. Further, the effect of vein compression before and while collecting the blood sample was also considered.

\section{Materials and Methods}

All of the trials used blood from clinically healthy, mature (5-10 years old) saddle-bred horses, which were not exercised intensively the day before blood sampling.

The blood was taken between 7:00-8:00 a. $\mathrm{m}$. from the jugular vein using vacuum vials, without or with only slight vein compression; plasma was separated by centrifugation (15 minutes at $2000 \mathrm{~min}^{-1}$ ) within one hour after sampling. Depending on the blood plasma specimen needed, the vials contained either sodium heparinate or EDTA (Becton Dickinson, No. 606457 and 606480).

The following influences on plasma ammonia concentration were investigated.

\section{Storage of EDTA plasma}

From six horses several vials of blood using EDTA as anticoagulant were taken. After centrifugation, aliquots of the plasma samples of each horse were stored at $20-22^{\circ} \mathrm{C}, 4^{\circ} \mathrm{C}$ and $-20^{\circ} \mathrm{C}$. The ammonia concentration was determined immediately after centrifugation and after $1,2,3$ and 7 days of storage at cach temperature; additionally, it was determined on day 21 for samples kept at $4{ }^{\circ} \mathrm{C}$ and $-20^{\circ} \mathrm{C}$.

\section{Storage of heparin plasma and comparison with EDTA plasma}

Five vials of blood containing heparin and five vials of blood containing EDTA as anticoagulant were obtained from one horse. Each vial was considered to be one sample and after 
centrifugation aliquots of each sample were stored at $4^{\circ} \mathrm{C}$ and at $-20^{\circ} \mathrm{C}$. Plasma samples kept at $4^{\circ} \mathrm{C}$ were assayed for ammonia immediately after separation and after three days of storage; frozen plasma samples were assayed immediately after separation and after 3 and 90 days of storage. Additionally, aliquots of the frozen heparin plasma samples were analyzed on days 10 and 21.

\section{Storage of EDTA whole blood}

From one horse several vials of EDTA-treated blood were collected. Five vials were centrifuged immediately after collection and the ammonia concentration was measured. The other vials were kept at $20-22^{\circ} \mathrm{C}$ or $4^{\circ} \mathrm{C}$ and one vial kept at each temperature was centrifuged after 1, 3, 6 and 26 hours of storage and the ammonia concentrations determined.

\section{Jugular vein compression}

From ten horses two blood samples were taken consecutively using EDTA-containing vials: one blood sample without compression of the jugular vein and the other blood sample after 30 seconds of strong compression of the vein with the thumb distal to the site of blood collection.

\section{Ammonia determination}

Before ammonia determination the plasma samples kept at $-20^{\circ} \mathrm{C}$ were thawed at $20-22^{\circ} \mathrm{C}$ and centrifuged for $3 \mathrm{~min}$ utes at $12000 \mathrm{~min}^{-1}$ in order to remove potential cryoprecipitates. Ammonia determination was done on an Eppendorf photometer at $334 \mathrm{~nm}$ with the Monotest Ammonia (Boehringer Mannheim, No. 125857), which uses NADPH as coenzyme. The within-day and day-to-day variability of the method amounted up to $11 \%$. The accuracy was determined with aqueous standard solutions of ammonia (Preciset Ammonia No. 166570 , Boehringer Mannheim) and did not exceed $10 \%$.

\section{Statistics}

The effect of influences on the ammonia concentration was investigated with variance analysis for repeated measures. The influence of storage duration on ammonia concentration in
EDTA plasma samples kept at different temperatures was calculated by regression analysis. The mean ammonia concentrations were compared using the t-test for dependent samples. The levels of significance used were: $\mathrm{p}<0.05, \mathrm{p}<0.01$ and $\mathrm{p}<0.001$.

\section{Results}

\section{Storage of EDTA plasma}

The ammonia concentration of EDTA samples stored at $-20^{\circ} \mathrm{C}$ did not change over 21 days. In contrast, the ammonia concentration in samples kept at $4^{\circ} \mathrm{C}$ and $20-22^{\circ} \mathrm{C}$ increased only 24 hours after collection. However, the rate of ammonia production differed. It amounted to $6.6 \mu \mathrm{mol} / \mathrm{l}$ per day at $4{ }^{\circ} \mathrm{C}$ and to $26.8 \mu \mathrm{mol} / \mathrm{l}$ per day at $20-22^{\circ} \mathrm{C}$ (fig. 1).

\section{Storage of heparin plasma and comparison with EDTA plasma}

The ammonia contents of the heparin plasma samples kept at $4{ }^{\circ} \mathrm{C}$ for three days were significantly above the concentrations measured on the day of sampling $(p<0.01)$. Ammonia was also increased in the heparin plasma samples stored at $-20^{\circ} \mathrm{C}$ after 21 days of storage ( $p<0.05$ and $p<0.01$, after 21 and 90 days, respectively; tab. 1). The changes of the ammonia content with time did not differ between the two anticoagulants used (tab. 1).

\section{Storage of EDTA whole blood}

In plasma obtained from EDTA whole blood kept at $4^{\circ} \mathrm{C}$ there was no significant change in the ammonia content after up to six hours of storage. However,

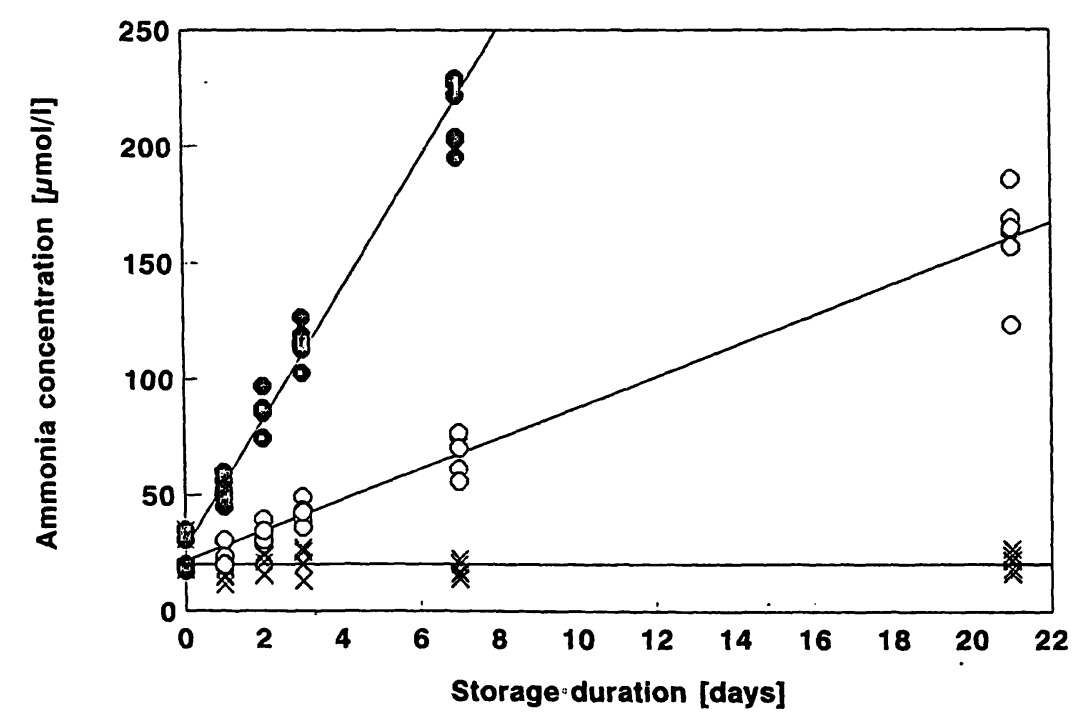

Fig. 1. Ammonia concentration of equine EDTA blood plasma samples stored at different temperatures $(n=6)$ $\begin{array}{rr}020-22^{\circ} \mathrm{C} y=26.8 x+28.7, r^{2}=0.98, p<0.001 \\ 0 & 4^{\circ} \mathrm{C} y=6.6 x+21.4, r^{2}=0.96, p<0.001 \\ x \quad-20^{\circ} \mathrm{C} y=0.03 x+20.1, r^{2}=0.001, p>0.05\end{array}$ 
Tab. 1. Ammonia concentration in equine EDTA and heparin blood plasma and its dependence on storage temperature and duration (mean \pm standard deviation; $n=5$ )

\begin{tabular}{llll}
\hline $\begin{array}{l}\text { Storage } \\
\text { duration } \\
\text { [days] }\end{array}$ & $\begin{array}{l}\text { Storage } \\
\text { temperature } \\
{\left[{ }^{\circ} \mathrm{C}\right]}\end{array}$ & \multicolumn{2}{c}{ Ammonia concentration $[\mu \mathrm{mol} / 1]$} \\
\cline { 3 - 4 } & - & $14.5 \pm 4.4$ & $15.3 \pm 3.4$ \\
\hline 0 & 4 & $41.2 \pm 12.5^{*}$ & $33.1 \pm 5.3^{* *}$ \\
3 & -20 & $13.7 \pm 2.3$ & $14.1 \pm 1.7$ \\
& -20 & - & $18.0 \pm 1.2$ \\
10 & -20 & - & $19.2 \pm 2.0^{*}$ \\
21 & -20 & $29.8 \pm 5.1^{* * * . a}$ & $31.3 \pm 3.9^{* *}$ \\
90 &
\end{tabular}

t-test for dependent samples between means of days for each anticoagulant $(\mathrm{n}=5)$ :

$*=\mathrm{p}<0.05$

$* *=\mathrm{p}<0.01$

$* * *=\mathrm{p}<0.001$

$a=$ in this case $n=4$

Tab. 2. Ammonia concentration in equine EDTA blood plasma and its dependence on storage temperature and duration of the whole blood samples (mean \pm standard deviation; $n=5$ )

\begin{tabular}{lll}
\hline $\begin{array}{l}\text { Storage } \\
\text { duration } \\
{[\mathrm{h}]}\end{array}$ & \multicolumn{2}{l}{ Plasma ammonia concentration $[\mu \mathrm{mol} / \mathrm{l}]$} \\
\hline & $\begin{array}{l}\text { Storage temperature } \\
{ }^{\circ} \mathrm{C}\end{array}$ & $20-22^{\circ} \mathrm{C}$ \\
\hline 0 & $17.4 \pm 2.5$ & $17.4 \pm 2.5$ \\
1 & $17.8 \pm 1.6$ & $23.8 \pm 11.5$ \\
3 & $10.4 \pm 11.5^{\mathrm{a}}$ & $25.2 \pm 1.8^{* *}$ \\
6 & $15.6 \pm 3.1^{\mathrm{a}}$ & $27.4 \pm 7.1^{*}$ \\
26 & $39.4 \pm 3.0^{\mathrm{b} . * *}$ & $76.6 \pm 13.2^{* * *}$ \\
\hline
\end{tabular}

t-test for dependent samples

- within means of samples at each time period with initial values for each temperature

$*=\mathrm{p}<0.05$

$* *=\mathrm{p}<0.01$

$* * *=\mathrm{p}<0.001$

- between mean of samples for each time period stored at different temperatures

$\mathrm{a}=\mathrm{p}<0.05$

$\mathrm{b}=\mathrm{p}<0.01$

after 26 hours ammonia values were significantly higher than baseline values $(p<0.01)$. Plasma ammonia values of EDTA-treated whole blood samples stored at $20-22^{\circ} \mathrm{C}$ already showed significant increases three hours after collection ( $p<0.01$; tab. 2$)$.

\section{Jugular vein compression}

The mean plasma ammonia concentration in EDTA blood samples collected without compression amounted to $23.4 \pm 4.3 \mu \mathrm{mol} / \mathrm{l}$, while it was 20.2 $\pm 4.1 \mu \mathrm{mol} / 1$ for the samples collected with compression. This difference was significant $(p<0.05)$.

\section{Discussion}

Although portable devices to measure ammonia under field conditions are available, the better standardization of methods under laboratory conditions generally allows more reliable results. Thus, depending on the time necessary to transport the specimens to the laboratory and on the amount of work to be done, it is important to know

a) how much time may elapse between blood collection and plasma ammonia determination; and

b) how the ammonia concentration may be maintained while allowing for sufficient time to perform the determination.

The data gained in our investigation on the stability of plasma ammonia in EDTA blood samples show clearly that plasma should be separated from the blood cells as soon as possible after collection of the specimens if the blood samples cannot be kept refrigerated. Under refrigeration it was possible to delay the separation for up to 6 hours. The importance of cell separation has been quantified for human blood samples $(11-14)$ and the rather slight changes most often described when the samples are kept at $4{ }^{\circ} \mathrm{C}$ using enzymatic test procedures also do not make immediate cell separation necessary for human blood $(11-13)$. It may be questioned even for plasma samples kept at room temperature as the ammonia production rate per hour has been quantified to be 1.4 $\mu \mathrm{mol} / \mathrm{l}(11)$.

For research purposes it is also of interest to know that the ammonia concentration does not increase markedly within 21 days if samples are kept frozen at $-20^{\circ} \mathrm{C}$. Similar results have been described for human plasma from healthy subjects by da FonsecaWollheim (15).

In the studies of Ogilvie et al. (10) the ammonia content of heparinized horse plasma samples kept frozen at $-20^{\circ} \mathrm{C}$ was very different from our results. They measured ammonia increases of more than $200 \%$ above initial values in plasma samples within 48 hours. One can only hypothesize as to cause of the much larger increase of ammonia observed in that study. A possible explanation may be that Ogilvie et al. (10) used a test kit with NADH as coenzyme while NADPH was used in our investigation. It has been discussed that, when NADH is used, the reaction of other enzymes such as lactate dehydrogenase and malate dehydrogenase and their substrates may seem to indicate higher ammonia values than are actually' present in a sample $(16-18)$. 
There is controversy in the literature about the effect of different blood anticoagulants on plasma ammonia content $(10,12,19-21)$. The results of this investigation allow the conclusion that EDTA and heparin do not show different effects on results of ammonia determination in equine blood plasma. The data obtained by Doumas et al. (20) for human blood plasma allow similar conclusions. Therefore, ammonia values obtained from blood anticoagulated with these two substances can very well be compared.

Another possible effect on plasma ammonia concentration can be neglected for horse blood: compression of the jugular vein. Further, the only experimental results described in the literature for humans dem-

\section{References}

1. Hageloch, W., Schneider, S. \& Weicker, H. (1990) Blood ammonia determination in a specific field test as a method supporting talent selection in runners. Int. J. Sports Med. 11, Suppl. 2, S 56-S 61.

2. Lehmann, M., Gendrisch, G., Kaminski, R., Peterke, E., Steffny, H., Schmid, P., Fischer, S., Baumann, H., Seidel, A., Wiesenack, C., Dickhuth, H. H. \& Keul, J. (1991) Trainingsumfang versus Intensität. Zwei prospektive, experimentelle Studien mit erfahrenen Mittel- und Langstreckenläufern. Dtsch. Z. Sportmed. 42, 480-491.

3. Lehmann, M., Dickhuth, H. H., Gendrisch, G., Lazar, W., Thum, M., Kaminski, R., Aramendi, J. F., Peterke, E., Wieland, W. \& Keul, J. (1991) Training - Overtraining. A prospective, experimental study with experienced middleand long-distance runners. Int. J. Sports Med. 12, 444452.

4. Schlicht, W., Witt, D.. Rohde, T., Mahlke, T. \& Wilhelm, A. (1988) Steuerung der Trainingsbelastung im Langsprint. Dtsch. Z. Sportmed. 39, 234-240.

5. Schlicht, W., Naretz, D., Witt, D. \& Rieckert, H. (1990) Ammonia and lactate: Differential information on monitoring training load in sprint events. Int. J. Sports Med. 11, Suppl. 2, S85-S 90.

6. Essen-Gustavsson, B. \& Valberg, S. (1987) Blood and muscle ammonia concentrations in horses during treadmill work and after racing. In: Equine Exercise Physiology 2 (Gillespie, J. R., Robinson, N. E., eds.) ICEEP Publications, Davis, CA. pp. 456-463.

7. Greenhaff, P. L., Harris, R. C., Snow, D. H., Sewell, D. A. \& Dunnett, M. (1991) The influence of metabolic alkalosis upon exercise metabolism in the thoroughbred horse. Eur. J. Appl. Physiol. 63, 129-134.

8. Harris, R. C., Marlin, D. J. \& Snow, D. H. (1987) Metabolic response to maximal exercise of 800 and $2,000 \mathrm{~m}$ in the thoroughbred horse. J. Appl. Physiol. 63, 12-19.

9. Harris, R. C., Marlin, D. J., Snow, D. H. \& Harkness, R. A. (1991) Muscle ATP loss and lactate accumulation at different work intensities in the exercising thoroughbred horse. Eur. J. Appl. Physiol. 62, 235-244.

10. Ogilvie, G. K., Engelking, L. R. \& Anwer, M. S. (1985) Effects of plasma sample storage on blood ammonia, bilirubin, and urea nitrogen concentrations: Cats and horses. Am. J. Vet. Res. 46, 2619-2622. onstrate clearly that the effect of vein compression on plasma ammonia concentrations is small (14).

The results gained in this investigation show that if certain handling procedures for equine blood are followed, the plasma ammonia content is stable enough to allow for a reliable ammonia measurement using samples taken in the field. The possible effect of the use of NADH instead of NADPH as coenzyme for measurements of equine blood plasma ammonia values remains to be investigated.

\section{Acknowledgement}

The authors would like to thank very much the mounted police squadron of Bonn-Hangelar for their cooperation and interest.

11. Da Fonseca-Wollheim, F. (1990 a) Preanalytical increase of ammonia in blood specimens from healthy subjects. Clin. Chem. 36, 1483-1487.

12. Howanitz, J. H., Howanitz, P. J., Skrodzki, C. A. \& Iwanski, J. A. (1984) Influences of specimen processing and storage conditions on results for plasma ammonia. Clin. Chem. 30, 906-908.

13. Da Fonseca-Wollheim, F. (1973) Direkte Plasmaammoniakbestimmung ohne Enteiweißung. Z. Klin. Chem. Klin. Biochem. 11, 426-431.

14. Prellwitz, W., Kapp, S. \& Dennebaum, R. (1976) Methodische Untersuchungen und klinische Bedeutung des Blutammoniaks. Med. Welt 27, 1277-1280.

15. Da Fonseca-Wollheim, F. (1990 b) Deamidation of glutamine by increased plasma $\gamma$-glutamyltransferase is a source of rapid ammonia formation in blood and plasma specimens. Clin. Chem. 36, 1479-1482.

16. Humphries, B. A., Melnychuk, M., Donegan, E. J. \& Snee, R. D. (1979) Automated enzymatic assay for plasma ammonia. Clin. Chem. 25, 26-30.

17. Neeley, W. E. \& Phillipson, J. (1988) Automated enzymatic method for determining ammonia in plasma, with 14-day reagent stability. Clin. Chem. 34, 1868-1869.

18. Pesh-Imam, M., Kumar, S. \& Willis, C. E. (1978) Enzymatic determination of plasma ammonia: evaluation of Sigma and BMC kits. Clin. Chem. 24, 2044-2046.

19. Conn, H. O. (1962) Studies on the origin and significance of blood ammonia. I. Effect of various anticoagulants on the blood ammonia determination. Yale J. Biol. Med. 35, $171-184$.

20. Doumas, B. T., Hause, L. L., Sciacca, R. D., Jendrzejczak, B., Foreback, C. C., Hoover, J. D., Spencer, W. W. \& Smock, P. L. (1979) Performance of the Du Pont aca ammonia method. Clin. Chem. 25, 175-178.

21. Kurahasi, K., Ishihara, A. \& Uehara, H. (1972) Determination of ammonia in blood plasma by an ion exchange method. Clin. Chim. Acta 42, 141-146.
Dr. A. Lindner
Institut für Anatomie, Physiologie
und Hygiene der Haustiere
Katzenburgweg 7-9
D-53115 Bonn
Bundesrepublik Deutșchland 